\title{
The impact of solvent characteristics on performance and process stability of printed carbon resistive materials
}

\author{
Bruce Philip, Eifion Jewell (1), David Worsley
}

(C) The Author(s) 2016. This article is published with open access at Springerlink.com

\begin{abstract}
Carbon conductive pastes deposited by screen printing are used in many commercial applications including sensors, $\mathrm{PCB}$, batteries, and $\mathrm{PV}$, and as such represent an important value-added coating. An experimental investigation was carried out into the role of the solvent on the drying characteristics, conductivity, and process consistency in screen printed carbon pastes. Four materials with solvent boiling points between 166 and $219^{\circ} \mathrm{C}$ were deposited at film thickness between 6 and $16 \mu \mathrm{m}$, and the sheet resistance and film thickness were measured after successive passes through an industrial dryer operating with an air temperature of $155^{\circ} \mathrm{C}$. Sheet resistances of $14 \Omega /$ sq. were obtained with the thicker films while thinner films produced a sheet resistance of 46 $\Omega /$ sq. Thinner films achieved a stable resistivity within a 2.5-min residence time, while the thicker films required a residence time in excess of $12.5 \mathrm{~min}$ to achieve a stable resistivity. As well as prolonging drying times, the higher boiling point increased the resistivity of the cured film. It is postulated that the lower resistance of the faster drying materials is a result of film stressing increasing inter particle contact. Process models indicate that multiple thin layers are a more efficient means of manufacture for the process parameters examined.
\end{abstract}

Keywords Carbon graphite paste, Drying, Resistivity

$\begin{array}{ll}\text { Abbreviations } \\ \text { BP } & \text { Boiling point } \\ \text { NC } & \text { Nitrocellulose } \\ \text { CUSUM } & \text { Cumulative sum of deviations } \\ \text { CNT } & \text { Carbon nanotubes } \\ \text { MWCNT } & \text { Multi-wall carbon nanotubes }\end{array}$

B. Philip, E. Jewell ( $₫)$, D. Worsley

SPECIFIC, Baglan Bay Innovation Centre, Swansea

University, Central Avenue, Baglan SA12 7XE, Wales, UK

e-mail: e.jewell@swansea.ac.uk

\section{Introduction}

Carbon conductive coatings are of high added value and have found widespread use in the electrochemical sensors, ${ }^{1}$ PCB resistors, ${ }^{2}$ printed heating elements, ${ }^{3}$ electromagnetic shielding, batteries, ${ }^{4}$ and super-capacitors $^{5}$ and are increasingly being considered as electrodes for DSSC ${ }^{6,7}$ and perovskite PV cells. ${ }^{8,9}$ They therefore represent a useful material set with application in many growing industries. The dominant manufacturing method being used is screen printing where paste materials are formulated such that they can be deposited on a fixed film thickness using a relatively simple patterning process.

Carbon/graphite materials are considered commercially mature, and little scientific research has been carried out regarding their performance in recent times; research focus being concentrated on more research attractive materials such as CNTs, MWCNTs, graphene, and their hybridization with conventional graphite materials. ${ }^{10}$ Some development has been carried out on the manipulation, through doping, of materials, predominantly for bio sensing applications. ${ }^{11}$ Where formulation studies have been carried out, these focused on the influence of the carbon/graphite relative proportions, ${ }^{12}$ the carbon/graphite physical and electrical characteristics, ${ }^{13,14}$ and the proportion of conductive material required for charge percolation through the cured film. ${ }^{15}$

A variety of binder systems are compatible with carbon/graphite materials, such as epoxy resins, alkyd resins, acrylic resins, polyurethane resins, or phenolic resins, and the choice is generally governed by the curing temperature, substrate which is being printed, film flexibility, and the resin compatibility with the final application. The choice of binder/binders is usually proprietary information held by manufacturers. The solvent dissolves the binder, controls the formulation 
viscosity, and controls the drying and curing process. The drying/curing is a common bottleneck in many manufacturing processes and this is also the case in screen printing of conductive materials, and thus, the use of a more volatile solvent potentially improves process productivity. However, in continuous operation, a more volatile solvent may also result in reduced process consistency due to viscosity variation ${ }^{16}$ and solvent absorption into polymer materials used in the process. ${ }^{17}$ During formulation, a compromise must therefore be made with regard to solvent volatility. The impact and mechanisms for the effect of solvent volatility on nanomaterial dispersions ${ }^{18}$ and PEDOT:PSS ${ }^{19,20}$ dispersions are established, but in materials where large particles are present, there is a dearth of information. The volatility of the solvent is reported to have an effect on nanoparticle distribution, ${ }^{18}$ and the subsequent polymer elastic modulus. ${ }^{21} \mathrm{~A}$ further impact of the solvent volatility is that it plays a major role in film stresses induced during drying, ${ }^{22,23}$ with faster evaporation leading to greater stress in the film. ${ }^{24,25}$ The impact of this residual stress on conductivity of carbon materials has not been reported.

The aim of the study was to understand the impact of solvent on the performance of the conductive NCbased materials, to investigate the role of solvent on the drying, film formation, and conduction in carbon graphite pastes, and to establish the role of the solvent on process consistency and stability. From this understanding, the material formulations and operating conditions can be optimized such that the maximum conductivity can be achieved with the minimum film thickness, material usage, and shortest drying time without sacrificing process stability.

\section{Method and materials}

\section{Material preparation and characterization}

All materials were manufactured using the same carbon graphite/carbon black proportion, the same nitrocellulose binder (Aldrich product ID 435066), and the same solvent proportion. This yielded four materials whose constituents were identical apart from the solvent. The solvent/solvent blends were chosen on the basis of their relative boiling point, as this primarily dictates the drying. The final composition of the materials was $31 \%$ carbon/graphite, $9 \%$ binder, and $60 \%$ solvent.

Thermogravimetric analysis (TGA) was used to establish the relative evaporative characteristics of the materials once formulated, which when combined with rheological data would provide an indicator of manufacturing capability. TGA analysis was carried out by a Perkin Elmer Pyris 1 analysis with a temperature ramp to $500^{\circ} \mathrm{C}$ over a period of $1 \mathrm{~h}\left(8^{\circ} \mathrm{C} / \mathrm{min}\right)$ in a nitrogen atmosphere. This heating rate is an order of magnitude slower than is experienced during the drying process but was selected as this was the limit which could produce repeatable results. The lower surface area-tovolume ratio of the sample placed in the TGA compared to the printed film resulted in inconsistencies between successive measurements at high heating rates due to effects such as sample surface skinning and splitting. During conventional drying, no such effects are seen as there is higher surface area per unit volume allowing more even and consistent drying. Continuation beyond the drying temperature was carried out in order to estimate the ratio of carbon to binder in the initial formulation. At $500^{\circ} \mathrm{C}$, all solvent and resin materials have been removed from the sample, leaving only the carbon black and graphite materials. TGA isotherms were carried out at 130 and $155^{\circ} \mathrm{C}$ as these represented the mean and peak substrate temperature experienced during the substrate passage through the dryer.

Material rheology was carried out using a Brookfield RS cone and plate viscometer operating through a constant stress shear ramp from 5 to $500 \mathrm{~Pa}$ with 50 intermediate steps. TGA analysis of the material, Fig. 1 and Table 1, shows that mass loss begins in earnest around $100^{\circ} \mathrm{C}$ with the peak evaporation between 154 and $178^{\circ} \mathrm{C}$. The position of peak mass loss (as defined by the minimum-dm/dT) is depicted in Fig. 1b, and this consistently occurs prior to the solvent

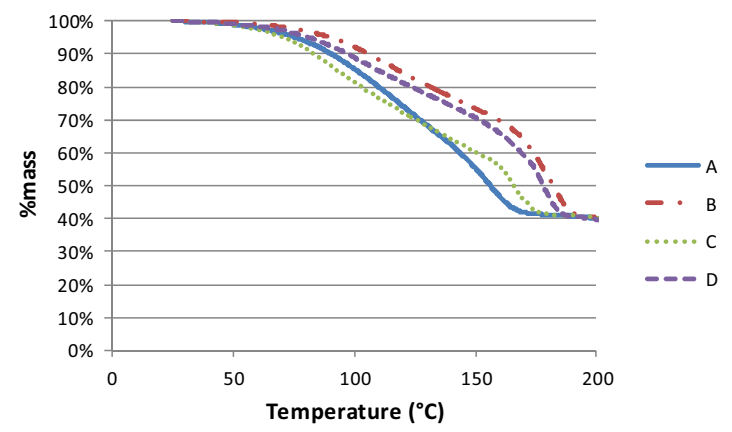

(a) TGA characteristics up to $200^{\circ} \mathrm{C}$

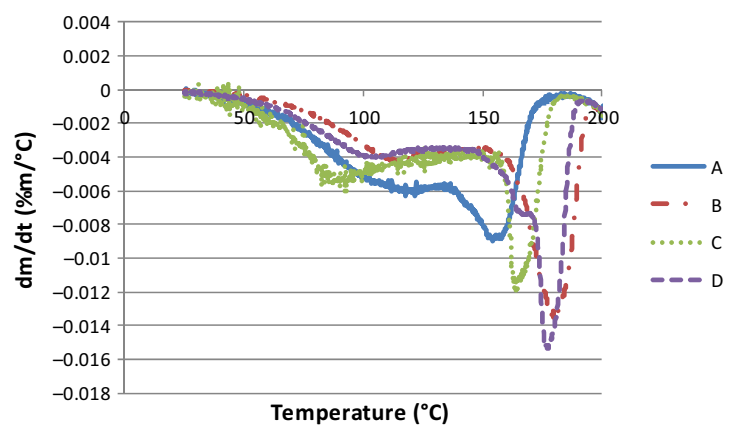

(b) $d m / d T$

Fig. 1: TGA analysis of the four materials. A: 4-Hydroxy-4Methyl-2 Pentanone, B: P-Menth-1-En-8-ol (Terpineol), C: 2-Butoxyethanol, D: 4-Hyrdroxy-4Methyl-2-Pentanone and P-Menth-1-En-8-ol (Terpineol) 
Table 1: Characteristics of the 4 materials as formulated

\begin{tabular}{lcccc} 
Solvents & $\begin{array}{c}\text { A } \\
\text { 4-Hydroxy-4-Methyl-2 } \\
\text { Pentanone }\end{array}$ & $\begin{array}{c}\text { B } \\
\text { P-Menth-1-En-8-ol } \\
\text { (Terpineol) }\end{array}$ & $\begin{array}{c}\text { C } \\
\text { 2-Butoxyethanol }\end{array}$ & $\begin{array}{c}\text { D } \\
\text { 4-Hydroxy-4Methyl-2-Pentanone \& } \\
\text { P-Menth-1-En-8-ol (Terpineol) }\end{array}$ \\
\hline Nominal solvent BP $\left({ }^{\circ} \mathrm{C}\right)$ & 166 & 219 & 171 & $166 \& 219$ \\
Peak mass loss TGA $\left({ }^{\circ} \mathrm{C}\right)$ & 154 & 178 & 163 & 177 \\
$\%$ Mass at & & & $92 \%$ & $95 \%$ \\
$80^{\circ} \mathrm{C}$ & $94 \%$ & $97 \%$ & $72 \%$ & $81 \%$ \\
$120^{\circ} \mathrm{C}$ & $74 \%$ & $84 \%$ & $60 \%$ & $71 \%$ \\
$150^{\circ} \mathrm{C}$ & $55 \%$ & $73 \%$ & $40 \%$ & $40 \%$ \\
$200^{\circ} \mathrm{C}$ & $40 \%$ & $40 \%$ & $31 \%$ & $31 \%$ \\
$500^{\circ} \mathrm{C}$ & $31 \%$ & $31 \%$ &
\end{tabular}

boiling point, although the difference between the peak loss and boiling point varies between solvents. All solvent is lost by $200^{\circ} \mathrm{C}$ leaving $40 \%$ solid material, and a further $9 \%$ mass is lost as the binder is decomposed by $500^{\circ} \mathrm{C}$ to $31 \%$, resulting in a $3.44: 1$ conductive:binder mass ratio.

Isothermal $\mathrm{TGA}$ measurement at $130^{\circ} \mathrm{C}$ indicate that all the solvent, given sufficient residence time, from A, C, and D will evaporate to form a solvent free solid film (asymptotic at 40\%), while material B (the terpineol-based material) does not achieve a steady state within the 30-min period allotted, Fig. 2a. At $155^{\circ} \mathrm{C}$, all materials reach an asymptotic $40 \%$ solids content, A, C, and D within 5 min, while B attains the $40 \%$ asymptote at around $9 \mathrm{~min}$.

\section{Coating deposition}

Each material was printed through four screens (Table 2) in order to examine the role of film thickness on the drying characteristics. The theoretical volume represents the geometric free air volume available within the mesh and is an indicator of film thickness only.

Printing was carried out on an ATMA AT-25PA screen printer with drying taking place in a $3 \mathrm{~m}$ Thieme conveyor tunnel dryer operating at $1.2 \mathrm{~m} / \mathrm{min}$ (residence time of $2.5 \mathrm{~min}$ ) and an air temperature of $155^{\circ} \mathrm{C}$ (the maximum permitted substrate temperature). This provides a favorable environment for substrate heating and mass transfer from the coating, as air is impinged at $155^{\circ} \mathrm{C}$ to the surface from an array of holes. Multiple passes were made through the tunnel dryer with electrical characterization being carried out at each intermediate stage on a cooled substrate. Five samples were made and manufactured at each experimental condition. Logged thermocouple traces were used to measure transient substrate temperatures through the dryer, Table 3 . The conductive carbon materials were printed to a $145 \mathrm{~mm} \times 145 \mathrm{~mm} \times 0.7 \mathrm{~mm}$ polymer- coated steel (TATA "Prisma”) substrate consisting of a polyurethane topcoat deposited onto a layer of organic primer atop a galvanized zinc on a steel substrate.

\section{Film characterization}

Dry film resistivity $\left(\rho=R_{\mathrm{s}} \times t\right)$ was the primary figure of merit used to compare the performance of the materials. The sheet resistance element of this was measured using a 4 point sheet resistance with $2 \mathrm{~mm}$ electrode spacing, and the subsequent sheet resistance was calculated using constants which reflect the geometric sizes being measured. ${ }^{26}$ Three measurements were made on each of 5 substrates measured. Measurements for a given condition were $\pm 1 \Omega /$ sq. Dry film thickness was measured using an Elcometer 456 measurement gauge with the thickness of the paint and galvanized coating removed to provide reference surface from which the conductive dry print film thickness could be calculated. The substrate possessed a regular embossed texture with an $\mathrm{Ra}$ of approximately $20 \mu \mathrm{m}$ and a period of approximately $2 \mathrm{~mm}$ which was felt could have an impact on film thickness measurement. An initial hundred repeat measurements of the thickness from polyurethane reference surface to steel substrate yielded a mean thickness of $60 \mu \mathrm{m}$ with a standard error of $0.35 \mu \mathrm{m}$. This standard deviation was mostly attributed to the embossed surface topology of the substrate, and as a result, 20 multiple measurements were taken of the reference surface and printed surface on each sample to reduce uncertainty yielding confidence of $\pm 0.6 \mu \mathrm{m}$.

\section{Results}

The presentation of the results will examine the role of the solvent on the curing characteristics of the printed film followed by examination of the role of solvent on key process consistency. 


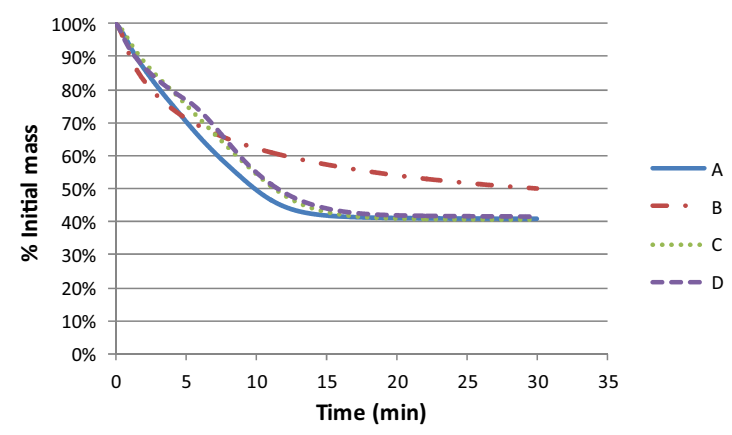

(a) $130^{\circ} \mathrm{C}$

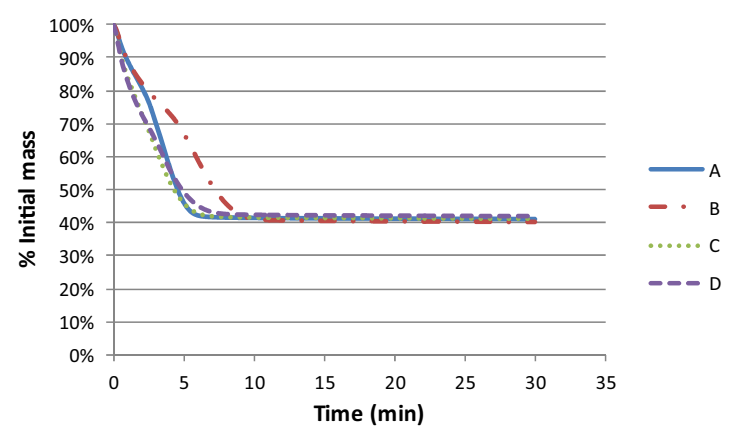

(b) $155^{\circ} \mathrm{C}$

Fig. 2: TGA isotherms at specified temperatures of 130 and $155^{\circ} \mathrm{C}$

Table 2: Screens used to dictate film thickness

\begin{tabular}{lrccr} 
Notation & $32-100$ & $61-64$ & $90-48$ & $110-34$ \\
\hline Mesh ruling (threads/cm) & 32 & 61 & 90 & 110 \\
Thread diameter $(\mu \mathrm{m})$ & 100 & 64 & 48 & 34 \\
Mesh aperture size $(\mu \mathrm{m})$ & 209 & 90 & 55 & 54 \\
Theoretical volume $\left(\mathrm{cm}^{3} / \mathrm{m}^{2}\right)$ & 73 & 30 & 19 & 19 \\
\hline
\end{tabular}

Table 3: Temperature/time characteristics for a single pass through the dryer

Temperature $\left({ }^{\circ} \mathrm{C}\right)$

Time at or above temperature (s)

\begin{tabular}{lr}
\hline 50 & 140 \\
100 & 120 \\
130 & 106 \\
140 & 84 \\
\hline
\end{tabular}

\section{Drying characteristics}

Once completely dried, sheet resistance values between 46 and $14 \Omega /$ sq. were obtained with film thicknesses between 6 and $16 \mu \mathrm{m}$, Fig. 3. There is some variation between material film thickness when printed through the identical screen. This could partly be associated with minor differences in rheological behavior between the materials caused by the solvent and partially due to the topological variations in the underlying surface. For this reason, further reporting of the data is carried out in terms of resistivity where film thickness variations are normalized. The sheet resistance generally follows a $1 /$ thickness relationship with reduced sheet resistance as film thickness increases.

The impact of drying on the conductivity is best illustrated by examining the resistivity for each material residence time at or above $130^{\circ} \mathrm{C}$ (the mean substrate temperature experienced by the samples during the passage through the dryer). Increasing residence time reduces the resistivity, and this reduction is more pronounced for the thicker films, Fig. 4a.
The effect of residence time is relatively insignificant for the thinner film thickness (finer meshes), Figs. 4c and $4 \mathrm{~d}$; thus, complete cure can be guaranteed within a single pass through the dryer (residence time at $130^{\circ} \mathrm{C}$ of $106 \mathrm{~s}$ ). For the thickest film (produced by the 32100 screens), a plateau resistivity is not achieved within $500 \mathrm{~s}$ residence time at $130^{\circ} \mathrm{C}$. Material B consistently provides the highest resistivity.

It is postulated that the faster drying rate observed with the lower BP solvents results in a greater internal tension across the upper layers of the film as the film is forced to contract at an increased rate. This internal tension leads to greater compressive force between the conductive particles. The compression leads to a greater particle/particle surface contact improving the percolation pathway, which subsequently aids charge transfer between the particles. Changes in carbon/ polymer resistance have been utilized previously in order to develop thin film force sensors, ${ }^{27,28}$ and thus, its impact post cure is established. Higher BP solvents with longer drying times allow reorganization of the conductive particle/polymer/solvent structure which seeks to reduce these inherent stresses in the film. ${ }^{24}$ The lower internal tension reduces the intimate contact between conductive particles, and therefore, higher resistances are obtained.

The net effect of the mesh used on the final cured plateau resistivity is shown in Fig. 5a, where the absolute final resistivity remains approximately constant for a given material, irrespective of the mesh being used, although there is a small increase in mean resistivity obtained with the finest mesh 110-34. Possible filtering action of the finer mesh is not the source of this difference as the mesh opening is approximately equal as is the available volume available to transfer to the substrate, Table 2 . The slight increase in resistivity with the 110-34 was therefore attributed to deviations in film surface topology which can present themselves as variations in measured film thickness. ${ }^{29}$ The change in resistivity (as defined by the change in resistivity between 1st dryer pass and stabilized resistivity) shows that the thinnest film achieves its stable resistivity within one pass, while thicker films (32/100) have a 
significant way to achieve their stable resistivity, Fig. 5 b.

The effect of film thickness on the degree of cure (as defined by the change in resistance between the first dryer pass and stabilized resistance) shows that increasing film thickness increases the resistance change non-linearly, Fig. 6. Thus, increasing film thickness in order to reduce final sheet resistance can result in a significant penalty in terms of drying time. There may be instances when depositing multiple thin layers to achieve a given target sheet resistance is more productive than depositing a single thick film.

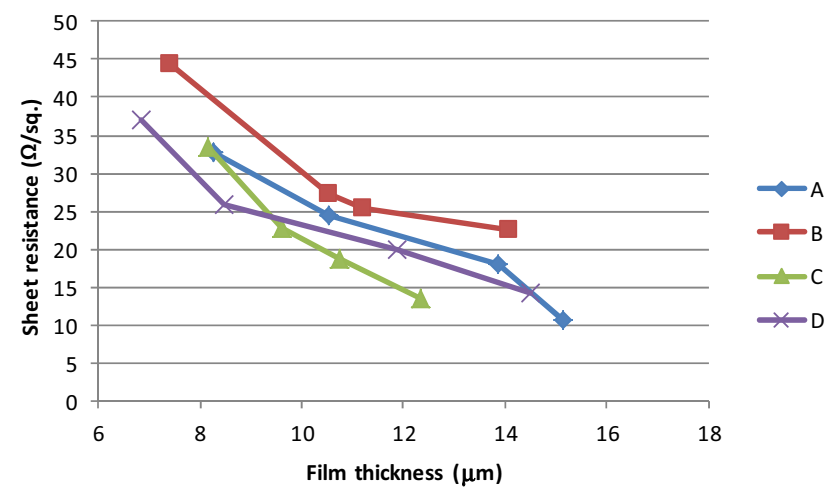

Fig. 3: Sheet resistance/film thickness relationship for the materials through each of the 4 screens

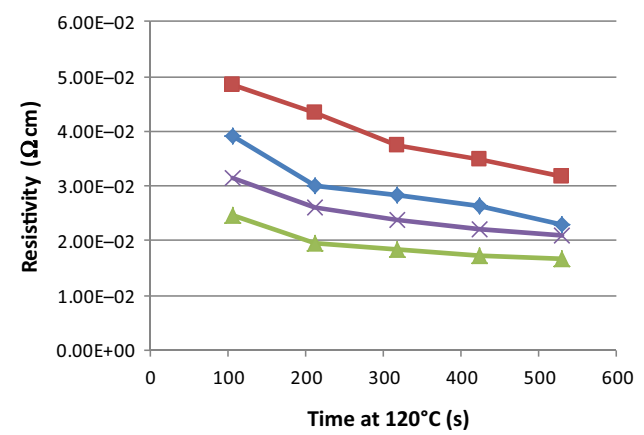

(a) $32-100$

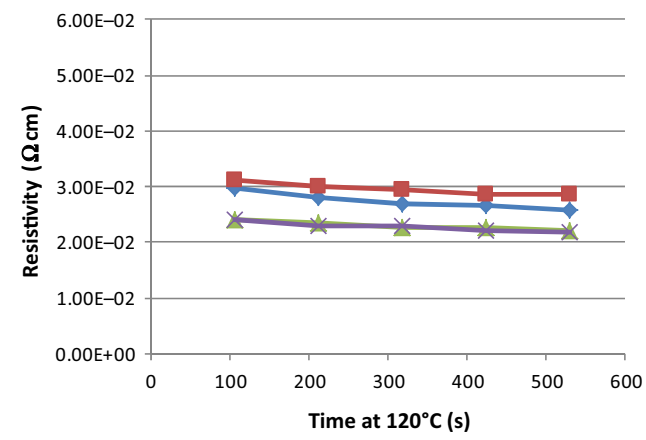

(c) $90-48$

\section{Solvent impact on process consistency}

The choice of solvent also impacts the process consistency through two primary mechanisms of solvent absorption into the squeegee (which softens the squeegee) and evaporation during processing, which leads to viscosity increases. In order to assess the role of the solvent on the performance of the squeegee, lengths were placed in $10 \mathrm{~mm}$ depth of each material for $3 \mathrm{~h}$. These lengths were then mounted in the printer and used immediately after printing substrate using a fresh, "dry" control squeegee. ${ }^{17}$ The net effect of squeegee exposure to the solvent was negligible for all the materials, Fig. 7, with the exception of material B, which produced a relatively small $3.5 \Omega /$ sq. increase in sheet resistance. This is in contrast to that observed previously ${ }^{17}$ in that solvent absorption into the squeegee caused softening and subsequent increases in film thickness (and hence a reduction in sheet resistance).

Potential solvent loss during processing was first examined by isothermal TGA simulations at $25^{\circ} \mathrm{C}$, Table 4. These values represent a relative measure of solvent loss and should not be taken as an indicator of mass loss in the machine over the production period as there is a significant variation in the sample mass/surface area ratio and air conditions between the TGA and printing environment.

In order to further investigate whether the evaporation of the solvent during printing would adversely

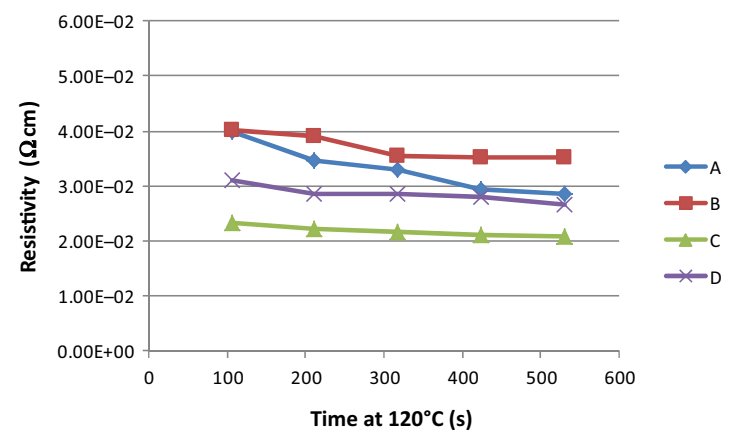

(b) 61-64

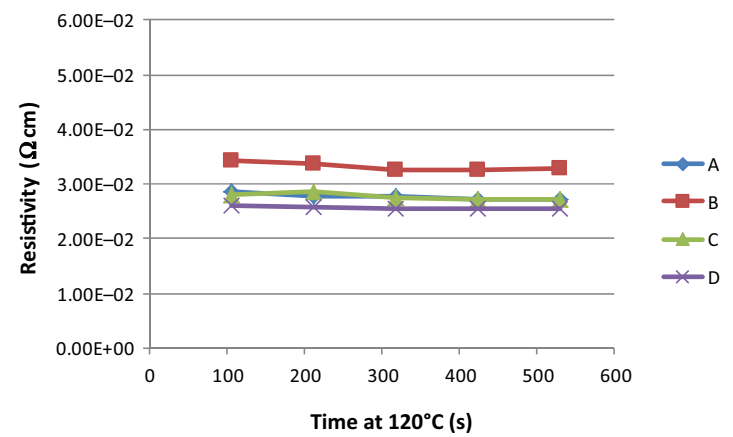

(d) 110-34

Fig. 4: Resistivity with exposure at $130^{\circ} \mathrm{C}$ for each formulation for each mesh type 


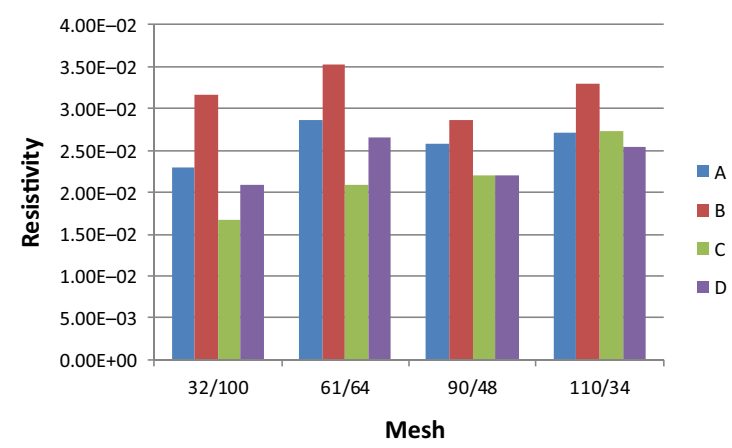

(a)

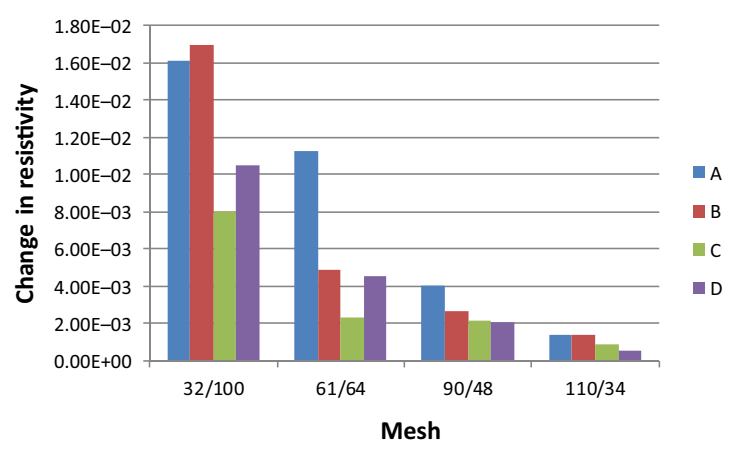

(b)

Fig. 5: Resistivity (a) and change in resistivity (b) for each material and each screen

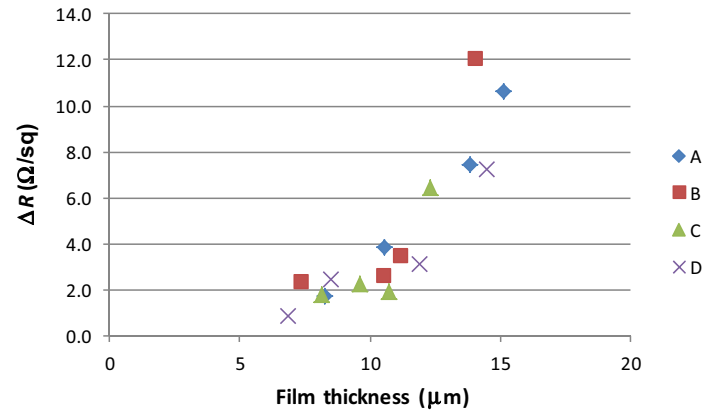

Fig. 6: Change in sheet resistance between single pass through dryer and stabilized sheet resistance for each material

affect the consistency of the process, the effect of solvent evaporation on material rheology was examined. Samples of material were allowed to evaporate naturally at room temperature, and the viscosity and mass loss were measured at regular intervals. This was carried out until the material was considered to be beyond the rheological limits of the screen printing process (typically up to $3 \%$ solvent loss). From this, it was possible to examine changes in rheological behavior due to solvent loss. All materials exhibit pseudoplastic behavior with viscosities of around 200 Pas at low shear plateauing viscosity to between 6 and 11 Pas at shear rates above $300 \mathrm{~s}^{-1}$, Fig. 8a. The highest viscosities were obtained with the terpineol based materials. Solvent loss produces a near linear increase in viscosity for each of the materials, Fig. $8 \mathrm{~b}$. The gradient of solvent loss to viscosity change is approximately equal for each material at a shear rate of $100 \mathrm{~s}^{-1}$. This relationship was observed throughout the shear rate range measured, with the exception of low shear below $10 \mathrm{~s}^{-1}$ where instrument sensitivity became an issue. Each material therefore undergoes approximately the same change in viscosity as it loses solvent, although the rate at which solvent is lost for materials $\mathrm{A}$ and $\mathrm{C}$ (more volatile solvents) is faster. The increased evaporation rate would be countered with lower initial viscosities, thereby providing a longer

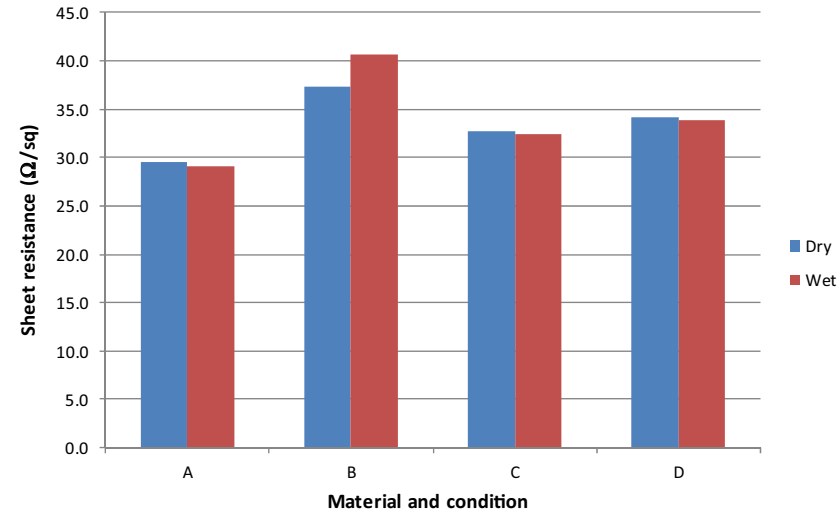

Fig. 7: Sheet resistance when the squeegee subjected to an extended period of exposure (wet) compared to a fresh squeegee (dry)

Table 4: Isothermal TGA measurements for $25 \mathrm{~min}$ at $25^{\circ} \mathrm{C}$ for each material

\begin{tabular}{ccccc} 
& A & B & C & D \\
\hline Mass loss \% & 2.28 & 1.02 & 2.79 & 1.84
\end{tabular}

period of time where the critical maximum process viscosity would be reached.

Having investigated the physical changes which may lead to process consistency issues, the net effect of these solvent factors was established by producing a short pilot run. In all, 50 samples were manufactured through the $90-48$ mesh at a rate of 2 samples/min. This relatively slow production rate, and the large surface area open to the atmosphere during printing was chosen to produce conditions beneficial for solvent loss. Each was subjected to a dryer residence time of $900 \mathrm{~s}$, ensuring complete cure for all materials. New squeegees were used for each material, and the laboratory was kept at a constant $20^{\circ} \mathrm{C}$ and $70 \%$ humidity. The sheet resistance was measured every five prints. The largest absolute variation (from the first print) for all the materials remain within a variation of 


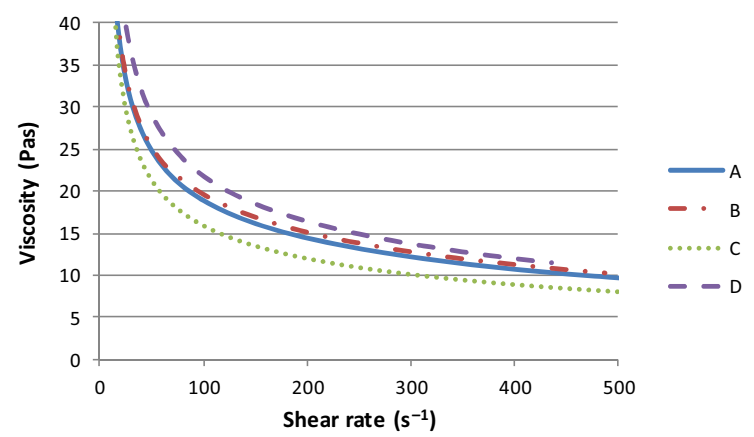

(a)

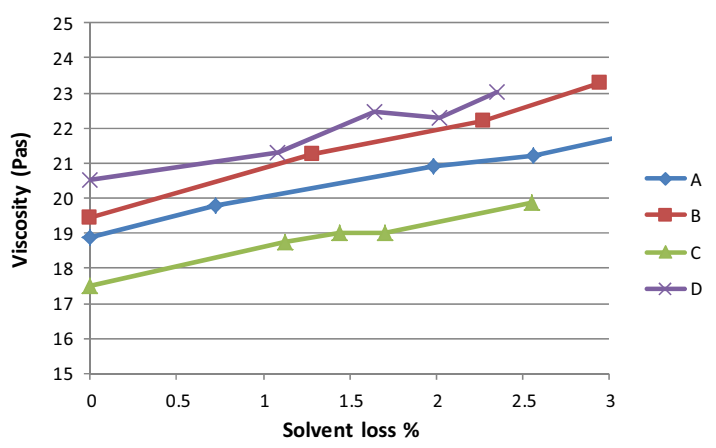

(b)

Fig. 8: (a) Viscosity profiles for each material as supplied and (b) the effect of solvent loss on the viscosity at a shear rate of $100 \mathrm{~s}^{-1}$

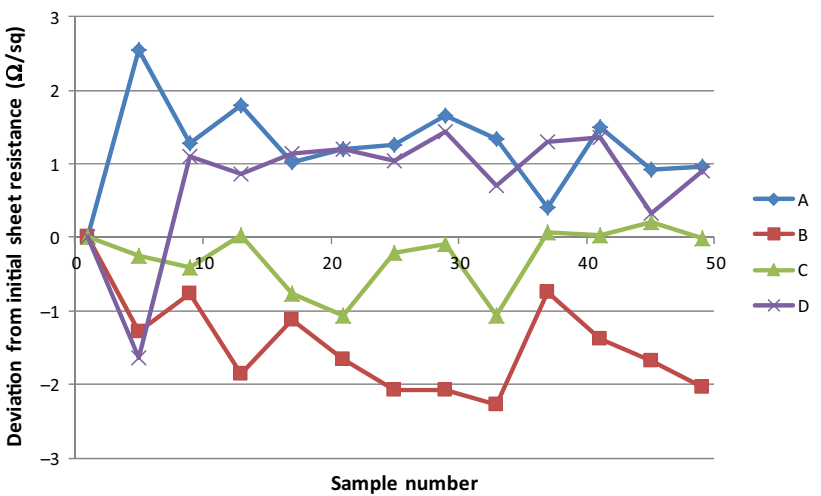

Fig. 9: Variation in sheet resistance through a pilot production run of 50 samples as a variation from the initial sample (measurement confidence of $\pm 1 \Omega / s q$ )

$\pm 2 \Omega /$ sq. for the entirety of the sample manufacturing run, Fig. 9, although there is no overall trend in resistance change through the pilot run.

Within the limits of the sample manufacturing run examined, there is no clear evidence that the relatively volatile nature of the material causes an increase in process variation. Thus, there may be further scope for utilizing a more volatile solvent, which would improve drying rate without a penalty in process consistency.

\section{Discussion}

It was postulated that the improved material resistivity observed with lower BP solvents was due to the increased film stressing associated with more rapid solvent loss which compresses the conductive particles. No clear evidence for this was observed during SEM and optical inspection of the film. The dense particulate and optical nature of the film does not allow optical stress of the film to be readily measured. Similarly, the rigid nature of the substrate does not allow its measurement by substrate curvature. In order to examine whether the film stress could be evaluated, the highest and lowest boiling point solvent materials were coated to a $38-\mu \mathrm{m}$ heat stabilized PET substrate and cured at $130^{\circ} \mathrm{C}$. The stress in the lower BP film is sufficient to delaminate the coating and produce a distinct curled free film, while the higher BP coating remains adhered and flat on the substrate, Fig. 10. Thus, the internal stress within the film is sufficient to overcome the adhesive forces of the coating to the substrate and cause a permanent change in film form. While this does not provide a correlation between the solvent $\mathrm{BP}$ and the induced stress, it provides qualitative evidence that a differential film stress exists. Given the conductivity effects shown previously, there is some verification of the hypothesis that the lower BP solvents induce higher conductivity through increased film stress. Further work is planned on providing a quantitative correlation.

The study has examined films with a dry film thickness of greater than $5 \mu \mathrm{m}$ and has examined the macrochanges in conductivity with respect to stepwise increases in residence time (as set by the number of passes through the dryer). Measurement of the evolution of conductivity through the wet film during the initial drying would be beneficial in understanding the role that the heating rate and solvent evaporation rate have on the conductivity of the final formed film.

The study has demonstrated that there is a drying time penalty which has to be paid as the film thickness is increased. Thus, where a high conductivity film is required, a choice must be made between a single thick coat or multiple thin coats. In such circumstances, the benefit in conductivity from additional film thickness needs to be balanced with additional drying time requirements, and in many instances, it would be beneficial to carry out multiple thin film printing and drying processes to optimize productivity. Using the data generated in the study, a model was created which related the total processing time to the primary final film specification of sheet resistance. This assumed a total printing and unloading operational time of $70 \mathrm{~s}$, a drying time of $150 \mathrm{~s}$ and that the sheet resistance 


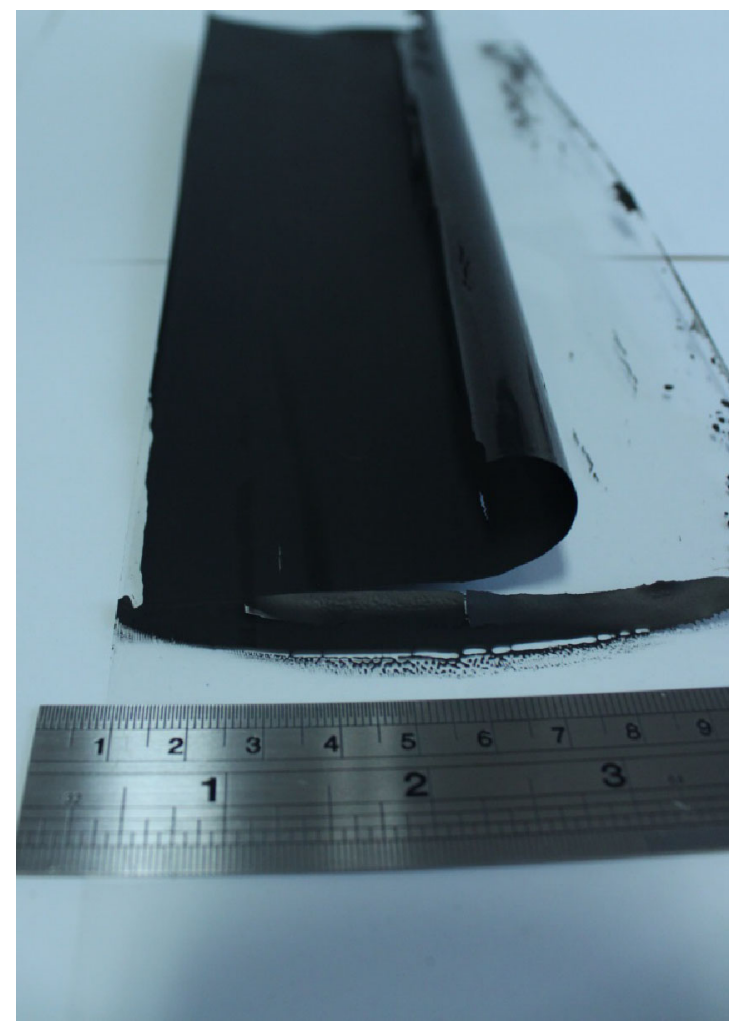

(a) Lowest BP

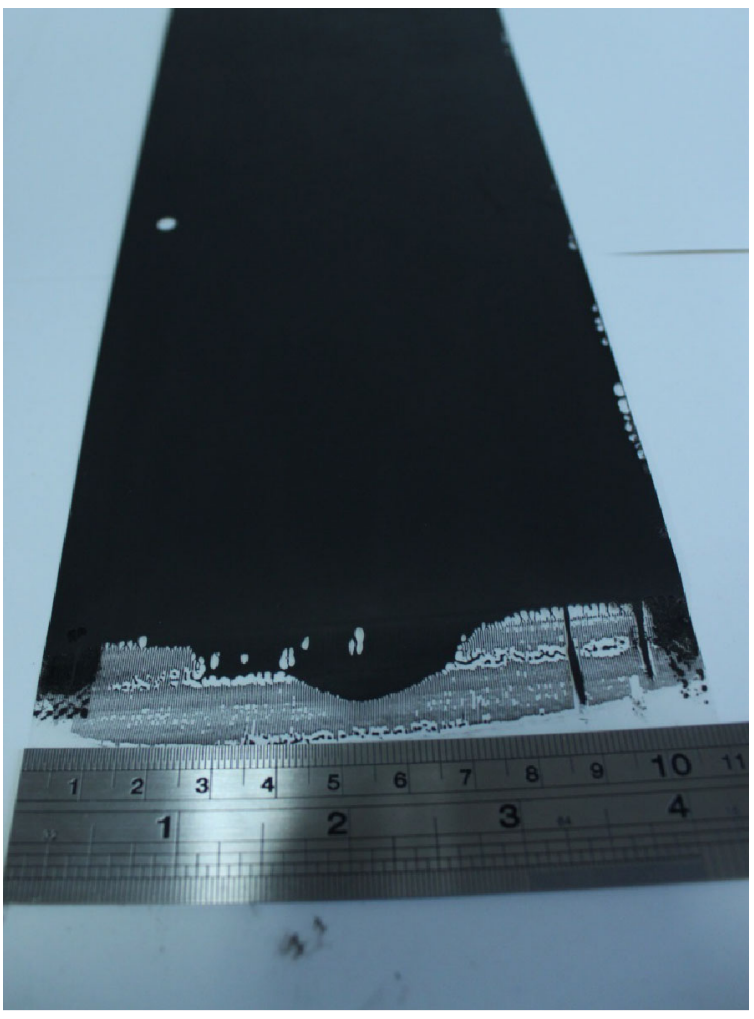

(b) Highest BP

Fig. 10: A comparison of samples coated to PET depicting the film stress which is sufficient to delaminate the coating to form a free standing curled film

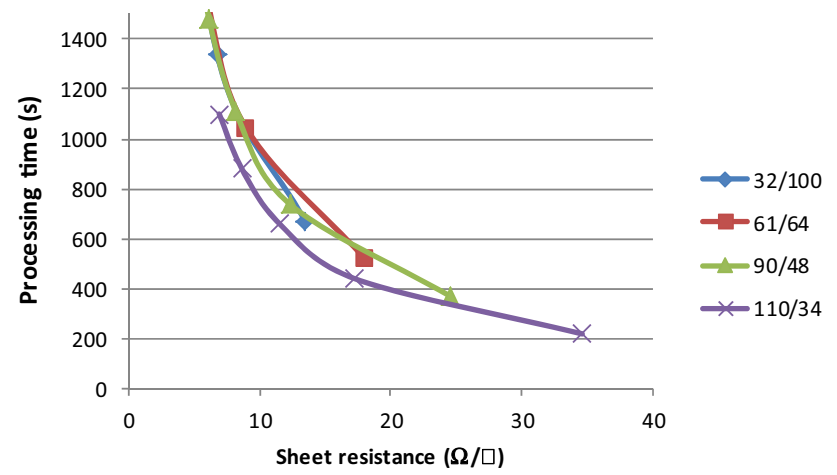

Fig. 11: Process time evaluation for material $\mathrm{C}$ for a range of sheet resistance

follows a $1 /$ thickness relationship. These criteria were applied to the most conductive material in the study (C), and the results of this analysis are shown in Fig. 11. It should be noted that the sheet resistance is only available at nominated integer number of layers and not the values between successive layers. Under all sheet resistivity values, the multiple deposition of thin layers provides a shorter processing time than that achieved with a single printing action and multiple drying stages. Thus, from a purely processing time viewpoint, it is beneficial to utilize high multiple printing processes in order to reduce the overall drying time. In practice, other factors may alter this strategy. These include cost and availability of the semi-skilled labor required for printing, process yields (where reductions are often seen in the printing process and seldom in the drying process), and availability of dryers facilitating longer residence times. A longer residence time would reduce the number of individual drying steps required for the thicker films but would do little to improve the thinner films which pass through a portion of the dryer in a fully dried state; thus, a portion of their processing time would be wasted. In addition, the impact of ink drying in the screen is likely to be higher with finer meshes as they would be more sensitive to the dried ink limiting the passage of ink through the screen.

Although no correlation was found between solvent volatility and process variation during a short 50 -sheet pilot manufacturing run, processes occurring over longer timescales may have an impact on product quality, and further work should examine process variations due to solvent volatility over a longer timescale. This should also address more hostile operating conditions which may be experienced in 
practice compared to the controlled $20^{\circ} \mathrm{C}$ under which the present study was carried out.

The study has direct impact for future manufacturing upscaling of glass-based perovskite PV where carbon is being considered as an electrode. The temperature sensitivity of the functional photonic layers $^{30}$ limits the thermal loading which can be imparted into the device, and as such, the choice of solvent, film thickness, and its subsequent conductivity will have a direct impact on the device efficiency.

\section{Conclusions}

An experimental study has been carried out on the relationship between solvent properties and the drying and electrical characteristics of a screen printable conducting carbon/graphite ink. The solvent plays a dominant role in the time required for drying and also plays an important role in determining the final resistivity of the cured film. It is postulated that this is a result of the stresses induced during the drying process which creates greater contact between the conductive particles in the cured film. The study has shown that the choice of a low volatility solvent has no detrimental effect on process consistency, either by solvent absorption into the squeegee or by evaporation leading to drying of the ink in the screen. The results indicate that, for the manufacturing speeds examined, multiple thinner films provided a more productive means of manufacture compared to a single thick film.

Acknowledgments The authors would like to thank the Coleg Cymraeg Cendlathol, EPSRC, Innovate UK and Welsh Assembly Government and Gwent Electronic Materials for their support of this study.

Open Access This article is distributed under the terms of the Creative Commons Attribution 4.0 International License (http://creativecommons.org/licenses/by/4.0/), which permits unrestricted use, distribution, and reproduction in any medium, provided you give appropriate credit to the original author(s) and the source, provide a link to the Creative Commons license, and indicate if changes were made.

\section{References}

1. Švancara, I, Vytřas, K, Kalcher, K, Walcarius, A, Wang, J, "Carbon Paste Electrodes in Facts, Numbers, and Notes: A Review on the Occasion of the 50-Years Jubilee of Carbon Paste in Electrochemistry and Electroanalysis." Electroanalysis, 21 7-28 (2009). doi:10.1002/elan.200804340

2. Cheng, PL, Leung, SYY, Law, TW, Liu, CK, Chong, JIT, Lam, DCC, "Quantitative Analysis of Resistance Tolerance of Polymer Thick Film Printed Resistors." IEEE Trans.
Compon. Packag. Technol., 30 269-274 (2007). doi:10.1109/ TCAPT.2007.897968

3. Serra, N, Maedera, T, Lemaire, P, Ryser, P, "Formulation of Composite Resistive Pastes for Micro-Heater Manufacturing." Procedia Chem., 1 48-51 (2009). doi:10.1016/j.proche. 2009.07.012

4. Moskon, J, Dominko, R, Cerc-Korosec, R, Gaberscek, M, Jamnik, J, "Morphology and Electrical Properties of Conductive Carbon Coatings for Cathode Materials." J. Power Sources, 174 683-688 (2007). doi:10.1016/j.jpowsour.2007.06.239

5. Pandolfo, AG, Hollenkamp, AF, "Carbon Properties and Their Role in Supercapacitors." J. Power Sources, 157 11-27 (2006). doi:10.1016/j.jpowsour.2006.02.065

6. Murakami, TN, Ito, S, Wang, Q, Nazeeruddin, MK, Bessho, T, Cesar, I, et al., "Highly Efficient Dye-Sensitized Solar Cells Based on Carbon Black Counter Electrodes." J. Electrochem. Soc., 153 A2255 (2006). doi:10.1149/1.2358087

7. Imoto, K, Takahashi, K, Yamaguchi, T, "High-Performance Carbon Counter Electrode for Dye-Sensitized Solar Cells." Sol. Energy Mater. Sol. Cells, 79 459-469 (2003). doi:10.1016/ S0927-0248(03)00021-7

8. Ku, Z, Rong, Y, Xu, M, Liu, T, Han, H, "Full Printable Processed Mesoscopic $\mathrm{CH}_{3} \mathrm{NH}_{3} \mathrm{PbI}_{3} / \mathrm{TiO}_{2}$ Heterojunction Solar Cells with Carbon Counter Electrode." Sci. Rep., 33132 (2013). doi:10.1038/srep03132

9. Zhang, L, Liu, T, Liu, L, Hu, M, Yang, Y, Mei, A, et al., "The Effect of Carbon Counter Electrodes on Fully Printable Mesoscopic Perovskite Solar Cells." J. Mater. Chem. A, 3 9165-9170 (2015). doi:10.1039/C4TA04647A

10. Park, HK, Kim, SM, Lee, JS, Park, J-H, Hong, Y-K, Hong, $\mathrm{CH}$, et al., "Flexible Plane Heater: Graphite and Carbon Nanotube Hybrid Nanocomposite." Synth. Met., 203 127-134 (2015). doi:10.1016/j.synthmet.2015.02.015

11. Śvancara, I, Walcarius, A, Kalcher, K, Vytřas, K, "Carbon Paste Electrodes in the New Millennium." Cent. Eur. J. Chem., 7 598-656 (2009). doi:10.2478/s11532-009-0097-9

12. Azim, SS, Satheesh, A, Ramu, KK, Ramu, S, Venkatachari, G, "Studies on Graphite Based Conductive Paint Coatings.' Prog. Org. Coat., 55 1-4 (2006). doi:10.1016/j.porgcoat. 2005.09.001

13. Dziedzic, A, "Carbon/Polyesterimide Thick-Film Resistive Composites-Experimental-Characterization and Theoretical Analysis of Physicochemical, Electrical and Stability Properties." Microelectron. Reliab., 47 354-362 (2007). doi:10.1016/j.microrel.2006.02.016

14. Celzard, A, McRae, E, Deleuze, C, Dufort, M, Furdin, G, Marêché, J, "Critical Concentration in Percolating Systems Containing a High-Aspect-Ratio Filler." Phys. Rev. B, 53 6209-6214 (1996). doi:10.1103/PhysRevB.53.6209

15. Lei, H, Pitt, WG, McGrath, LK, Ho, CK, "Resistivity Measurements of Carbon-Polymer Composites in Chemical Sensors: Impact of Carbon Concentration and Geometry." Sens. Actuators B Chem., 101 122-132 (2004). doi:10.1016/ j.snb.2004.02.042

16. Jewell, EH, Claypole, TC, Gethin, DT, "Viscosity Control in the Screen Printing of Ceramic Transfers." Surf. Coat. Int. B, 86 155-163 (2003). doi:10.1007/BF02699628

17. Jewell, EH, Claypole, TC, Gethin, DT, "The Effect of Exposure to Inks and Solvents on Squeegee Performance." Surf. Coat. Int. B Coat. Trans., 87 253-260 (2004)

18. Kim, D, Jeong, S, Park, BK, Moon, J, "Direct Writing of Silver Conductive Patterns: Improvement of Film Morphology and Conductance by Controlling Solvent Compositions." Appl. Phys. Lett., 89 87-90 (2006). doi:10.1063/1.2424671 
19. Nardes, AM, Janssen, RAJ, Kemerink, M, “A Morphological Model for the Solvent-Enhanced Conductivity of PEDOT:PSS Thin Films." Adv. Funct. Mater., 18 865-871 (2008). doi:10.1002/adfm.200700796

20. Xia, Y, Ouyang, J, "PEDOT:PSS Films with Significantly Enhanced Conductivities Induced by Preferential Solvation with Cosolvents and Their Application in Polymer Photovoltaic Cells." J. Mater. Chem., 214927 (2011). doi:10.1039/c0jm04177g

21. Ruschau, GR, Yoshikawa, S, Newnham, RE, "Resistivities of Conductive Composites." J. Appl. Phys., 72 953-959 (1992). doi:10.1063/1.352350

22. Francis, LF, McCormick, AV, Vaessen, DM, Company, EK, "Development and Measurement of Stress in Polymer Coatings." J. Mater. Sci., 37 4717-4731 (2002)

23. Ree, M, Chu, CW, Goldberg, MJ, "Influences of Chain Rigidity, In-Plane Orientation, and Thickness on Residual Stress of Polymer Films." J. Appl. Phys., 75 1410-1419 (1994). doi:10.1063/1.356422

24. Katsumata, R, Ata, S, Kuboyama, K, Ougizawa, T, "Evaporation Rate Effect on Starting Point of Shrinkage Stress Development During Drying Process in Solvent Cast Polymer Film." J. Appl. Polym. Sci., 128 60-65 (2013). doi:10.1002/app.38132

25. Dušková-Smrčková, M, Dušek, K, "Processes and States During Polymer Film Formation by Simultaneous
Crosslinking and Solvent Evaporation." J. Mater. Sci., 37 4733-4741 (2002). doi:10.1023/A:1020843020379

26. Smits, FM, "Measurement of Sheet Resistivities with the Four Point Probe." Bell Syst. Tech. J., 37 711-718 (1958). doi:10.1002/j.1538-7305.1958.tb03883.x

27. Knite, M, Teteris, V, Kiploka, A, Kaupuzs, J, "PolyisopreneCarbon Black Nanocomposites as Tensile Strain and Pressure Sensor Materials." Sens. Actuators A Phys., 110 142-149 (2004). doi:10.1016/j.sna.2003.08.006

28. Pham, GT, Park, YB, Liang, Z, Zhang, C, Wang, B, "Processing and Modeling of Conductive Thermoplastic/ Carbon Nanotube Films for Strain Sensing." Compos. B Eng., 39 209-216 (2008). doi:10.1016/j.compositesb.2007. 02.024

29. Petersen, I, Hübner, G, Claypole, TC, Jewell, E. Influence and Interaction Phenomena of Screen Printing Machine Settings on Surface Roughness. 38th International Research Conference. Advances in Printing and Media Technology, 2011, p. 1-9.

30. Bryant, D, Greenwood, P, Troughton, J, Wijdekop, M, Carnie, M, Davies, M, Wojciechowski, K, Snaith, H, Watson, T, Worsley, D, “A Transparent Conductive Adhesive Laminate Electrode for High Efficiency Organic-Inorganic Lead Halide Perovskite Solar Cells." Adv. Mater., 26 7499-7504 (2014). doi:10.1002/adma.201403939 